\title{
Variation of small strain stiffness for piping-influenced Toyoura sand
}

\author{
Yang Yang \\ Department of Geotechnical Engineering College of Civil Engineering, Tongji University, China \\ R. Kuwano \\ Institute of Industrial Science, the University of Tokyo, Japan \\ $\mathrm{Xu}$ Chao \\ Department of Geotechnical Engineering College of Civil Engineering, Tongji University, China
}

\begin{abstract}
Landslides triggered by piping are frequently reported during stormy periods. Despite large amount of model tests related with internal erosion, there is little research on the mechanical properties of disturbed soil by means of element experiment. In this paper, an attempt was made to create artificial piping by dissolving water soluble material (glucose) in sand. Chains of voids were generated when water was infiltrated and drained out through the specimen. Small torsional cyclic loadings were conducted on the hollow cylindrical specimens in order to obtain the small strain stiffness of the soil before/after piping erosion. According to the results, reduction of shear modulus was found in specimen with internal pipes after water infiltration, and piping-induced anisotropy was found to be obvious.
\end{abstract}

\section{INTRODUCTION}

\subsection{Background}

Piping occurs when water flows through a cavity, crack or other continuous void within the soil. Internal erosion in the form of piping is found to be responsible for a larger number of cases according to the statistics of dam failures (Foster et al., 2000; Uchida et al., 2001; Wilson et al., 2007). Recently, evidence that piping flow had taken place subsurface was often noticed by the collapses of macropores along the slopes in landslides reports. Such unstable soil structure with internal defects would have significant impact on the hydraulic conductivity of the ground, even lead to the recurrence of another landslide.

In order to obtain a more precise prediction on the behavior of soil subjected to internal erosion, quantitative evaluation of its mechanical properties is essential. Previous investigations related to piping always focus on the factors governing its initiation by means of model test (Wan et al., 2004; Bonelli et al., 2006; Lin Ke \& Akihiro Takahashi, 2012), including geometric conditions, loading conditions and hydraulic gradient. Besides that, there still exists a gap between the erodible particles and the geotechnical properties of the soil.

Inspired by the practice of using water soluble material (sugar, salt and glucose) to create loosened sand, proposed by Kuwano and Renuka (Renuka et al. 2011, 2012) in the study of ground cavity, the authors came up with the idea of recreating piping ef- fect in laboratory with glucose pipes. With the dissolving of the erodible particles (glucose), a preferential water path will be generated, simulating the piping formation. In this way, not only the sand loosening associated with piping propagation can be captured using local strain measuring devices, also the variation in the stiffness characteristics of the disturbed specimen could be obtained by experimental techniques.

\subsection{Small strain stiffness}

Under piping erosion, it is foreseeable that a new soil structure would be induced due to the particle detachment. Although it has been identified by many researchers that piping loosens the soil structure and reduces the soil's shear strength, how the preexisting defaults influences the soil stiffness and how the anisotropy brought from the weakened plane have still remained in question. In this study, besides the progression of the piping process, another primary concern will be the small strain, elastic shear modulus, which is of great importance not only in the ground deformational predication under earthquakes, machine foundations and other dynamics loadings, but also in the numerical modeling of slopes with potential erodible plane.

Techniques currently used to measure the small strain shear modulus in the laboratory include resonant column test, the bender element method and torsional shear test. With the development of accurate measurement of local strains, in triaxial apparatus or torsional shear apparatus, devices including 
the non-contact proximity transducer (Gap sensor), the LVDT, local deformation transducer (LDT), and pin-typed local deformation transducer (P-LDT) et al. were widely used (Hird and Yung, 1987; Cuccovillo and Coop, 1997; Goto et al., 1991; HongNam and Koseki, 2005). In the current research, shear modulus was obtained with the help of gap sensors by conducting small torsional cyclic loadings. The stiffness characteristics of soil at the initial dry state, after the piping formation, and during the rotation of major principal stress were investigated. Hollow cylindrical specimens with vertical pipe or horizontal pipe were made. Properties of the disturbed sand, which possesses a special anisotropic fabric formed during internal erosion, were studied in detail.

\section{TRIAXIAL TESTS}

\subsection{Apparatus}

In this study, a high-capacity torsional shear test apparatus developed at the Institute of Industrial Science, University of Tokyo was employed.

The apparatus mainly consists of a cell, loading system and measurement devices. The loading system is composed by an AC servo-motor, a reduction gear system with two gears, electronic magnetic clutches and brakes, which is controlled automatically by a computer. As shown in Figure 1, the vertical load $F$ and torque $T$ were applied on the hollow cylindrical specimen simultaneously and independently by two servo-motors and measured through a twocomponent load cell. Cell pressure is applied through an electro-pneumatic transducer (E/P) with a capacity of $1000 \mathrm{kPa}$, and measured by high capacity differential pressure transducer (HCDPT). Low capacity differential pressure transducer (LCDPT) is used to measure the volume change of inner hollow, which is fully filled with de-aired water, by the difference in water heads between two burettes with one collecting water from inner hollow and the other as a reference. Throughout the tests, the cell and LCDPT are connected by a stiff nylon tube. Thus, inner and outer cell pressures are equal to each other, i.e., the radial stress $\sigma_{r}$ is equal to the circumferential stress $\sigma_{\theta}$.

\subsection{Specimen preparation}

Toyoura sand from batch $J$ was used in this study, which is uniformly graded sand with sub-angular particles. The index properties of the sand are $\mathrm{G}_{s}=$ 2.64, $e_{\max }=0.992, e_{\min }=0.678$. Hollow cylindrical specimens (outer diameter $\mathrm{D}_{o}=10 \mathrm{~cm}$, inner diameter $\mathrm{D}_{i}=6 \mathrm{~cm}$ and height $\mathrm{H}=10 \mathrm{~cm}$ ) were prepared by air-pluviation method.

Glucose pipes both in vertical and horizontal were prepared in this study. For vertical glucose pipe, a plastic straw of $6.0 \mathrm{~mm}$ in diameter was placed in advance and fixed by iron wire, with the other end fastened to the four steel poles of the apparatus. After completing the sand pluviation, the dry glucose powder was filled into the straw. Then special care was taken to remove the straw so as to minimize disturbance of the surrounding sand. In this way, erosion could be induced only in the preformed cylindrical path in order to simulate the piping phenomenon. As for the horizontal pipe, small glucose blocks were made by mixing the powder with approximately $5 \%$ of water. After compacted into the mould of a hollow steel pipe with $5.5 \mathrm{~mm}$ in diameter, the mixture was pushed out and cut into small blocks with $1 \mathrm{~cm}$ in length. These blocks would be placed at mid-height of specimen in a circle during pouring of sand. Figure 2 shows the top view of the two types of samples.

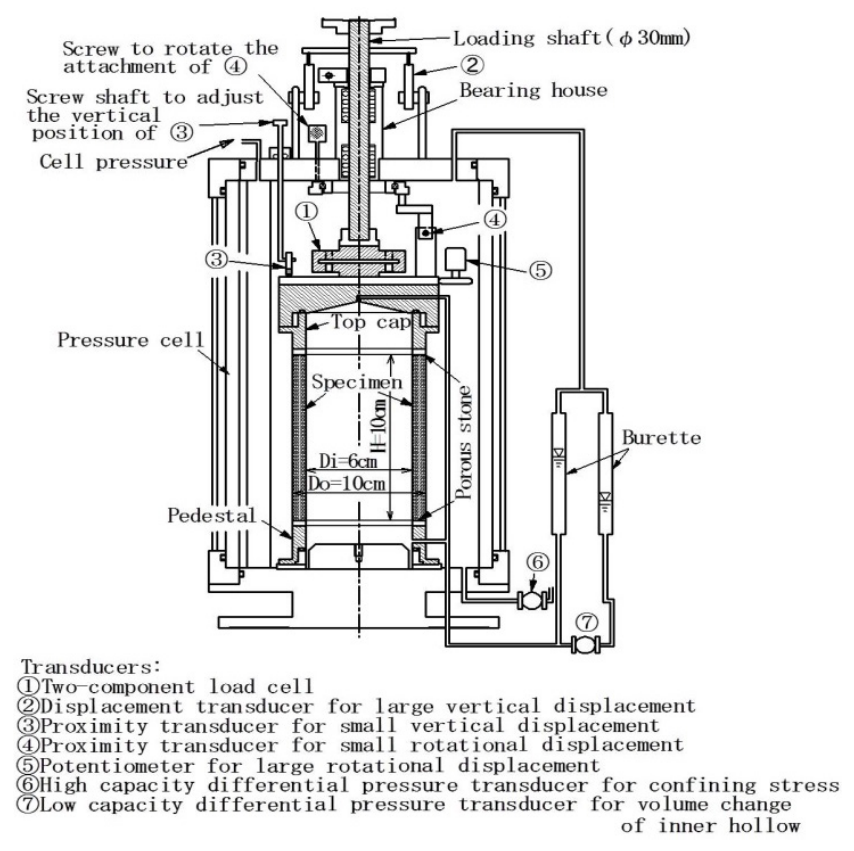

Figure 1. Hollow cylindrical specimen and transducers.
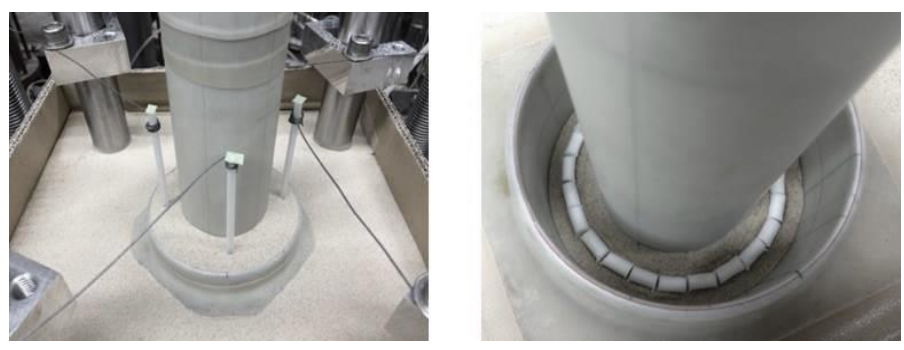

Figure 2. Specimen with internal glucose pipes.

\subsection{Test procedure}

After setting up the specimen, the effective pressure was increased to $80 \mathrm{kPa}$ and the specimen was isotropically consolidated for around 12 hours to dissipate the creep effect. Then small torsional cyclic loadings with peak to peak stress amplitude of $3 \mathrm{kPa}$ were conducted in order to obtain the initial shear modulus $G_{0}$ at dry state. After that, $1300 \mathrm{ml}$ of de- 
aired water was infiltrated into the specimen from the bottom pedestal to completely dissolve the glucose and induce the erosion. The inflow rate, measured by the two load cells hung upon the upper and lower water tanks, was controlled at around 12 $\mathrm{ml} / \mathrm{min}$. Then the specimen was sent to another creep state under drained condition for 10 hours, following by the second small cyclic loadings to examine shear modulus of the disturbed specimen $G_{1}$.

The next step was to increase $\sigma_{\mathrm{z}}$ while decreasing $\sigma_{\mathrm{r}}$ and $\sigma_{\theta}$ to keep the mean effective pressure constant, and the direction of $\sigma_{1}$ from vertical was 0 . Later, with the separate control of $\sigma_{\mathrm{z}}, \sigma_{\mathrm{r}}$ and $\tau$, direction of major principal stress was changed from $0^{\circ}$ to $180^{\circ}$. For every $10^{\circ}$ interval, small torsional cyclic loadings were conducted under the constant normal stresses. Figure 3 presents the measured stress path for the case of "NP_10" (referred Table 1).

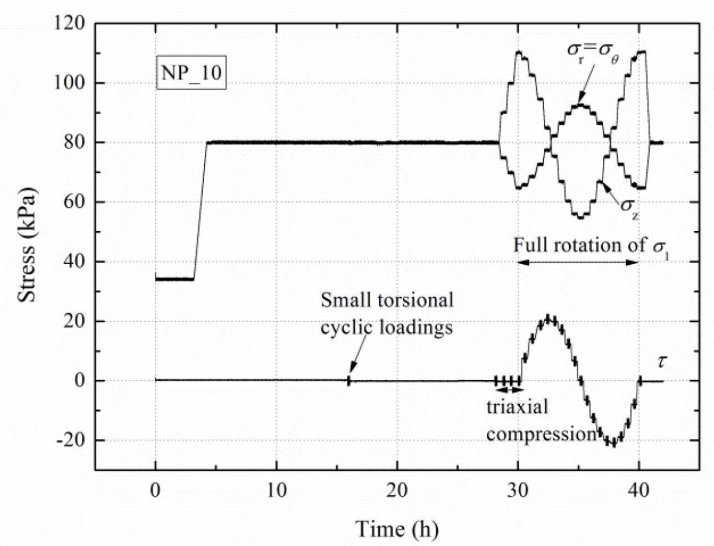

Figure 3. Variation of normal stresses.

As summarized in Table 1, six tests in total were conducted, which could be divided into Group 1 and Group 2 based on the stress ratio during rotation of principal stresses. Here "NP", "HP" and "VP" stand for no-pipe, horizontal-pipe and vertical-pipe respectively; and the subsequent " 10 " and " 15 " represent mobilized angle of internal friction $\phi_{m o b}$ at $10^{\circ}$ and $15^{\circ}$, corresponding to the stress ratio $R$ of 1.42 and 1.70. The computation of $\phi_{m o b}$ is presented in Equation 1. By keeping $p$ ' and $R$ constant, the evolution of shear modulus due solely to the rotation of principal stresses could be investigated.

Table 1. Test conditions.

\begin{tabular}{lllllll}
\hline Test ID & $\begin{array}{l}D_{\text {rini }} \\
(\%)\end{array}$ & $e_{\text {ini }}$ & $\begin{array}{l}\text { Pipe } \\
\text { number }\end{array}$ & $\begin{array}{l}\text { Pipe } \\
\text { direction }\end{array}$ & $\begin{array}{l}\mathrm{p} \\
(\mathrm{kPa})\end{array}$ & $\sigma^{\prime}{ }_{1} / \sigma^{\prime}{ }_{3}$ \\
\hline NP_10 & 72.0 & 0.711 & 0 & - & 80 & 1.42 \\
\hline HP_10 & 74.7 & 0.707 & 4 & Vertical & 80 & 1.42 \\
\hline VP_10 & 78.9 & 0.691 & 1 & Horizontal & 80 & 1.42 \\
\hline NP_15 & 73.0 & 0.713 & 0 & - & 80 & 1.70 \\
\hline HP_15 & 72.9 & 0.713 & 4 & Vertical & 80 & 1.70 \\
\hline VP_15 & 78.0 & 0.694 & 1 & Horizontal & 80 & 1.70 \\
\hline
\end{tabular}

$\emptyset_{\mathrm{mob}}=\sin ^{-1}\left(\frac{\sigma_{1}-\sigma_{3}}{\sigma_{1}+\sigma_{3}}\right)$

\section{STRESSES AND STRAINS IN TORSIONAL SHEAR}

Four stress components on the specimen in hollow cylinder torsional shear apparatus, namely axial stress $\left(\sigma_{\mathrm{z}}\right)$, radial stress $\left(\sigma_{\mathrm{r}}\right)$, circumferential stress $\left(\sigma_{\theta}\right)$ and shear stress $\left(\tau_{z}\right)$ can be defined by controlling the vertical axial load $\left(F_{\mathrm{z}}\right)$, the torque $(T)$, outer cell pressure $\left(p_{\mathrm{o}}\right)$ and the inner cell pressure $\left(p_{\mathrm{i}}\right)$. The relationship among the above stress and loading components are as follows (Hight et al., 1983):

$$
\begin{aligned}
\sigma_{z} & =\frac{F_{z}}{\pi\left(r_{o}^{2}-r_{i}^{2}\right)}+\frac{\left(p_{o} r_{o}^{2}-p_{i} r_{i}^{2}\right)}{\left(r_{o}^{2}-r_{i}^{2}\right)} \\
\sigma_{r} & =\frac{\left(p_{o} r_{o}+p_{i} r_{i}\right)}{\left(r_{o}+r\right)} \\
\sigma_{\theta} & =\frac{\left(p_{o} r_{o}-p_{i} r_{i}\right)}{\left(r_{o}-r\right)} \\
\tau_{z \theta} & =\frac{3 T}{2 \pi\left(r_{o}^{3}-r_{i}^{3}\right)}
\end{aligned}
$$

where $r_{o}$ and $r_{i}$ are the outer and inner radius of the specimen. $r_{i}$ is calculated by the data collected from LCDPT, and $r_{o}$ is obtained by averaging the results from three clip gauges. As is shown in Figure 4 , they are fixed at the outside the specimen with the support of aluminum blocks glued on the membrane.

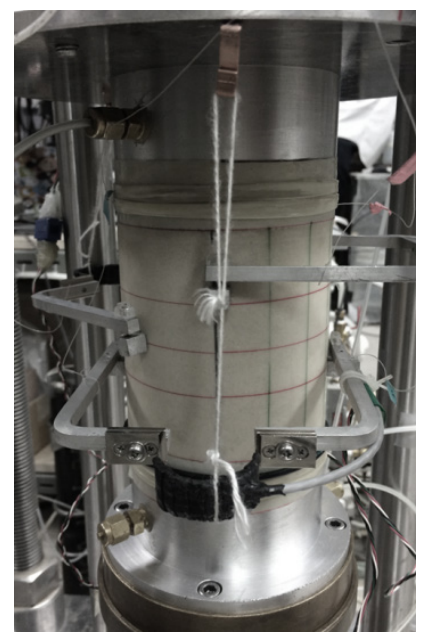

Figure 4. Arrangement of clip gauges.

As mentioned above, the vertical strain $\varepsilon_{\mathrm{V}}$ is measured by the external displacement transducer (EDT), and shear strain $\gamma_{z}$ is obtained by one pair of gap sensors (GS1 and GS2) with capacity of $4 \mathrm{~mm}$. In order to calculate the radial strain $\varepsilon_{r}$ and circumferential strain $\varepsilon_{\theta}$, two assumptions were made: i) the specimen remained right cylinder for the inner hollow, and ii) the sand influenced by piping effect is 
$1 / 4$ of the total volume for vertical-pipe-specimen and $1 / 5$ for horizontal-pipe-specimen for simplicity.

Figure 5 shows an example of the calculation of $G$ measured by gap sensors from the $10^{\text {th }}$ small clockwise/anticlockwise torsional cycles.

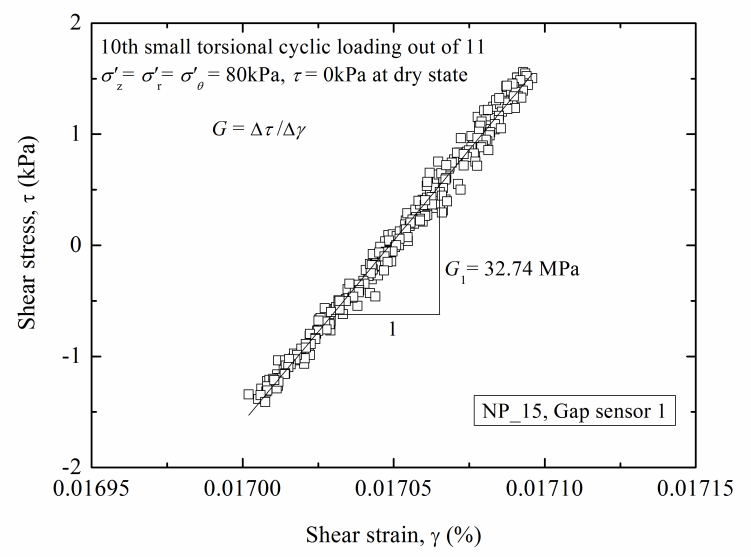

Figure 5. Evaluation of $G$ measured by GS1 from the $10^{\text {th }}$ cycle out of 11 during isotropic consolidation in NP 15 .

\section{RESULTS}

\subsection{Volumetric strain}

Figures 6-7 showed the volumetric strain variation during the whole test for all the specimens. It should be noted that the volume proportion of glucose to the total specimen is about $2.22 \%$ for four vertical glucose pipes and $1.17 \%$ for horizontal glucose pipe.

When the confining pressure was increased from $30 \mathrm{kPa}$ to $80 \mathrm{kPa}$, larger compression took place in the vertical-pipe-specimen for both of the two groups. For the horizontal-pipe-specimen and nopipe-specimen the increments in volumetric strain were nearly the same. One possible reason may lie in the more vulnerable structure in VP-specimen under the combined effect of bedding plane (in horizontal for air-pluviated sample) and vertical piping plane.

During water infiltration, the growth in volumetric strain was $1.34 \%$ for VP-specimen, $0.42 \%$ for HP-specimen and $0.12 \%$ for NP-specimen in Group 1 where $\phi_{\text {mob }}=10^{\circ}$, and for Ground 2 they were $1.78 \%, 0.47 \%$, and $0.04 \%$. These differences observed between specimens with the same amount of initial glucose indicated the unpredictable manner of the disturbance during the generation and propagation of piping. For VP-specimen, $\Delta \varepsilon_{\mathrm{vol}} / \varepsilon_{\text {glucose }}$ was between $60 \% \sim 80 \%$, while for HP-specimen, the value was around $36 \% \sim 40 \%$, indicating that loosening effect was more uniform in VP-specimen. In other words, a larger ratio of voids was left inside the HP-specimen given the initial proportion of glucose. This implies the higher risk on the stability of the slope when the direction of weaken planes coincide with the orientation of the layer.
For simplicity, volume of void induced by the glucose was calculated by Equation 6 .

$\varepsilon_{\text {void }}=\varepsilon_{\text {glucose }}-\Delta \varepsilon_{\text {vol }}$

Although void ratio near the initial glucose pipe was much different from the surrounding part due to the non-uniformity caused by the dissolution of glucose, change of the average void ratio could be calculated based on the data from local sensors. As is shown in Table 2, the proportion of voids left inside $\left(\Delta \varepsilon_{\text {void }}\right)$, which also implying the degree of piping, was positively associated with the variation of void ratio.

Table 2. Volumetric variation during piping generation.

\begin{tabular}{llccl}
\hline Test ID & $\begin{array}{c}\varepsilon_{\text {glucose }} \\
(\%)\end{array}$ & $\begin{array}{c}\Delta \varepsilon_{\text {vol }} \\
(\%)\end{array}$ & $\begin{array}{c}\Delta \varepsilon_{\text {void }} \\
(\%)\end{array}$ & $\Delta e_{\text {average }}$ \\
\hline HP_10 & 1.17 & 0.42 & 0.75 & 0.012 \\
\hline VP_10 & 2.22 & 1.34 & 0.88 & 0.015 \\
\hline HP_15 & 1.17 & 0.47 & 0.70 & 0.011 \\
\hline VP_15 & 2.22 & 1.78 & 0.44 & 0.008 \\
\hline
\end{tabular}

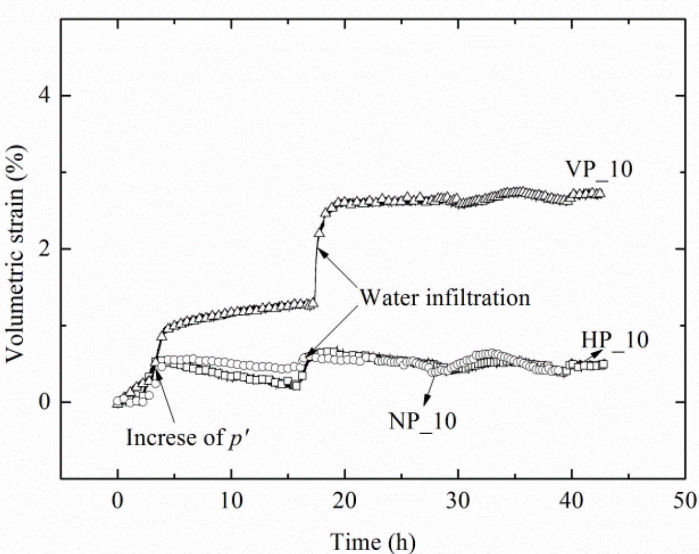

Figure 6. Variation of volumetric strain for Group 1.

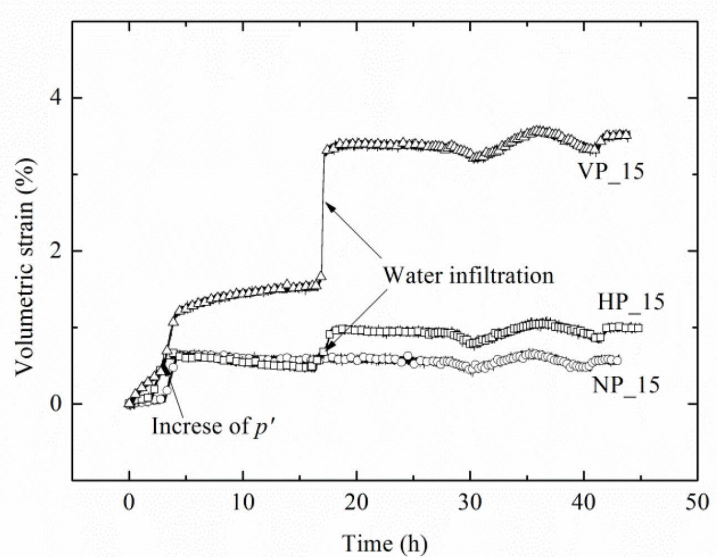

Figure 7. Variation of volumetric strain for Group 2. 


\subsection{Reduction of shear modulus due to piping effect}

The initial shear modulus of the dry sand under isotropic consolidation of $80 \mathrm{kPa}$ was denoted by $G_{0}$, and $G_{1}$ stood for the shear modulus of the disturbed specimen after water infiltration. Figure 8 shows the change of $G$ values before/after water infiltration, normalized by the void ratio function $f(e)=(2.17$ $e)^{2} /(1+e)$ (Hardion, B.O. and Richart Jr., F. E., 1963).

Smaller $G$ values were observed for all the specimens after water injection, and a more obvious reduction was found in specimens subjected to piping effect. In average $G_{1}$ is about $10.8 \%$ lower than $G_{0}$ for HP-specimen and $16.4 \%$ for VP-specimen, indicating that a larger range of piping-induced erosion would cause the greater degradation in shear modulus.

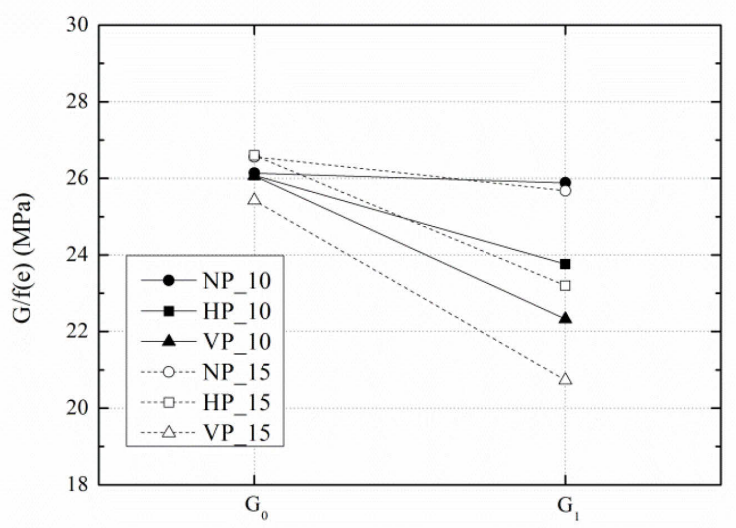

Figure 8. Reduction of shear modulus after water infiltration.

\subsection{Variation of shear modulus during triaxial compression}

Before the rotation of principal stresses, $\sigma_{z}$ was increased to the predetermined value, and $\sigma_{\mathrm{r}}$ as well as $\sigma_{\theta}$ was decreased simultaneously, while keeping the mean effective pressure constant. This could be taken as the process of triaxial compression without applying of $\tau$, seen in Figure 3. During this period, small torsional cyclic loadings were applied for every increment of $10 \mathrm{kPa}$ of the vertical stress after a creep around 15 minutes.

Figure 9 is the result of normalized shear modulus aginst $\left(\sigma_{\mathrm{z}} \cdot \sigma_{\theta}\right)^{0.5}$ in the full logarithmic plot. Here, the hypoelastic model named IIS model proposed recently by HongNam and Koseki (2005) was adopted, which was based on the regression results collected from triaxial and torsional cyclic loadings with the help of a newly developed pin-typed local deformation transducer on the dense Toyoura sand. The expression is:

$G_{\mathrm{ij}}=\frac{f(e)}{f\left(e_{0}\right)} \frac{G_{\mathrm{ij} 0}}{\sigma_{0}^{\mathrm{n}}}\left(\sigma_{\mathrm{i}}^{\prime} \sigma_{\mathrm{j}}^{\prime}\right)^{\frac{\mathrm{n}}{2}}\left(1-C_{\mathrm{G}} k_{\mathrm{n}}^{2}\right)$
In Equation 7, besides the void ratio and related stresses, effects of damage to the soil structure during shearing at high stress ratio were also considered by adding the factor of $k_{\mathrm{n}}$ and the correction factor $C_{\mathrm{G}}$.

During triaxial loadings (Figure 9) without rotation of principal stress axes, almost linear relationships were found between $G / f(e)$ and $\left(\sigma_{z} \cdot \sigma_{\theta}\right)^{0.5}$ on the full-logarithmic plot. The average values of $n$ varied with the condition of specimen, and a smaller $n$ was obtained for specimens with vertical pipes, indicating the predominant role of the weaken planes in the stiffness characteristics of soil.

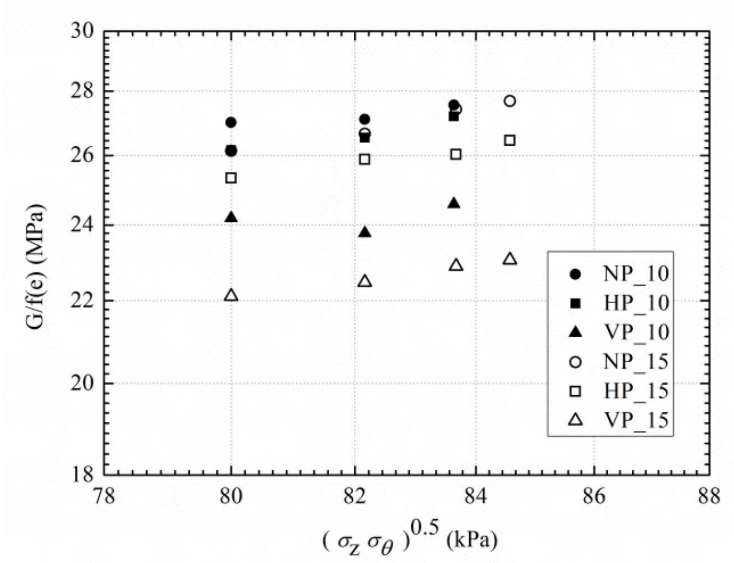

Figure 9. Shear modulus variation during triaxial compression.

\subsection{Variation of shear modulus during rotation of principal stresses}

Figures 10-11 show the variation of the normalized shear modulus against $\alpha$ during the rotation of principal stress from $0^{\circ}$ to $180^{\circ} . \alpha$ is the direction of the major principal stress from vertical, calculated by Equation 8.

$\tan 2 \alpha=\frac{2 \tau}{\left(\sigma_{\mathrm{z}}-\sigma_{\theta}\right)}$

As illustrated in Figures 10-11, for all the specimens, relationships between normalized shear modulus and $\alpha$ during the rotation of principal stresses were close to parabola. The value of $G / f(e)$ decreased first and showed a tendency of growing again when shear stress was applied anticlockwise (i.e. $\alpha$ over $90^{\circ}$ ). With more initial glucose inside, VP-specimen revealed the smallest value of shear modulus. For NP-specimen, a minimum value of shear modulus appeared when $\alpha$ equaled $90^{\circ}$; while for those disturbed specimens, more fluctuation appeared, indicating a more unstable structure. Particularly, under the combined influence of existed piping plane and bedding plane, VP-specimen behaved in a more random manner.

When comparing the results between these two groups, it could be found that the lower the stress ra- 
tio was, the smaller reduction in the value of $G / f(e)$ at the same $\alpha$.

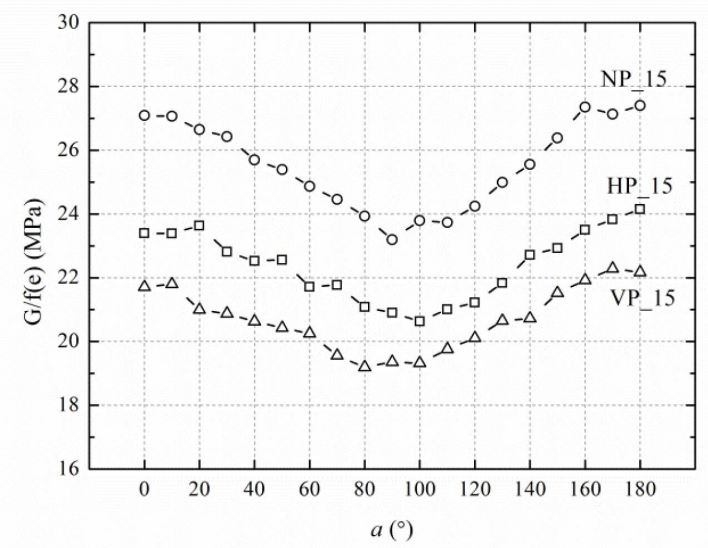

Figure 10. Variation of shear modulus against $\alpha$ for Group 1.

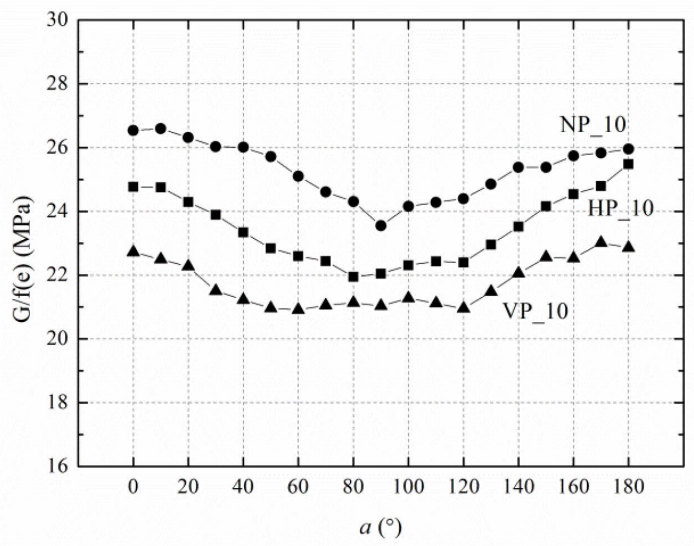

Figure 11. Variation of shear modulus against $\alpha$ for Group 2.

Besides the triaxial loadings, dependency of $G / f(e)$ on $\left(\sigma^{\prime}{ }_{z} \sigma_{\theta}\right)^{0.5 n}$ was also observed during the rotation of principal stress axes, seen in Figures 1213. The power $n$ obtained in this study was in the range of $0.685 \sim 1.051$, while in the research of HongNam (2005), $n$ was found to be in the range around $0.444 \sim 0.653$, which might be attributed to the disturbed specimen itself and the rotation of principal stress axes.

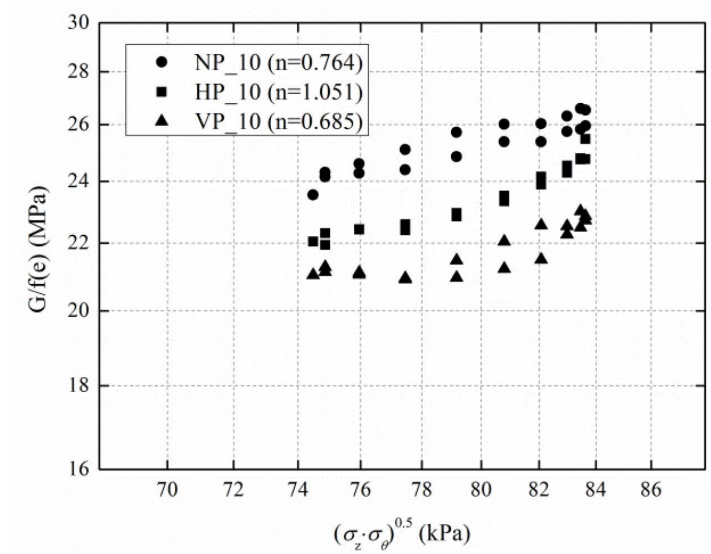

Figure 12. Relationship between $G / f(e)$ and $\left(\sigma^{\prime}{ }_{\mathrm{z}} \cdot \sigma^{\prime}{ }_{\theta}\right)^{0.5}$ during rotation of principal stress for Group 1.

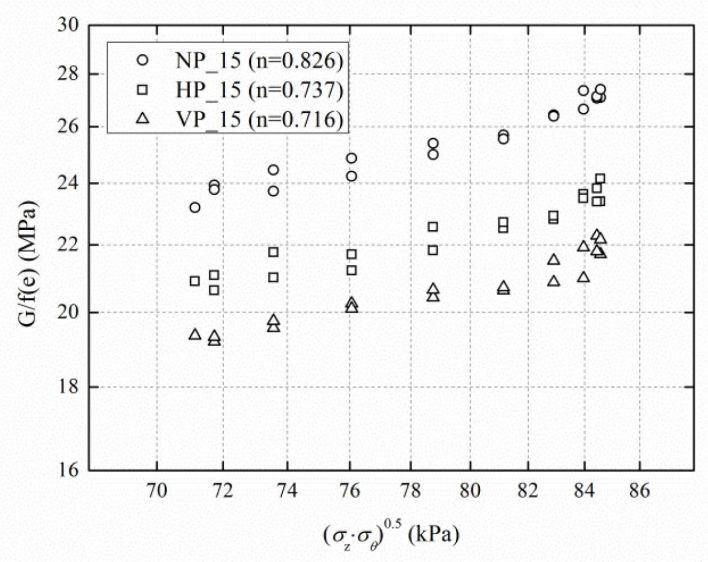

Figure 13. Relationship between $G / f(e)$ and $\left(\sigma_{\mathrm{z}}^{\prime} \cdot \sigma^{\prime}{ }_{\theta}\right)^{0.5}$ during rotation of principal stress for Group 2.

\section{CONCLUSIONS}

In this study, loosening effect was successfully reproduced by glucose in Toyoura sand, offering a new method to investigate soils with defection. Small strain properties of piping-effected Toyoura sand were investigated for the first time, which is of great importance in the deformation prediction of slopes with interconnected open pores and planning of preventative measures. The following conclusions could be drawn.

1. Based on the initial glucose content, a higher percentage of volumetric strain increment during piping formation at isotropic stress state was observed in specimen with internal vertical pipes than the horizontal one under the vertical water infiltration.

2. Reduction of shear modulus was caused by piping effect.

3. Degree of piping could be considered as the difference between the initial erodible particles and the volume change of the specimen during erosion, which was reflected in the variation of void ratio $e$.

4. Reformed soil structure would induce an unpredictable behavior, particularly when the orientation of the eroded plane is not inconsistent with the material axes.

5. Besides triaxial loading, $G$ could also be modelled by $\left(\sigma^{\prime}{ }^{\prime} \sigma_{\theta}^{\prime}\right)^{0.5 n}$ during torsional shearing with rotation of principal stress.

\section{ACKNOWLEDGEMENTS}

The authors would like to thank Mr. Takeshi Sato from Institute of Industrial Science for the indispensable assistance in the apparatus. This research was financially supported by China scholarship council and Broadvision Engineering Consultants (no. 2015(A)12). 


\section{REFERENCES}

Bonelli, S., Brivois, O., Borghi, R., Benahmed, N. 2006. On the modeling of piping erosion. Comptes Rendus Mecanique, 334: 555-559.

Cuccovillo, T. \& Coop, M. R. 1997. The measurement of local axial strain in triaxial tests using LVDT's. Geotechnique. 47(1), 167-171.

Foster, M. A., R. Fell, M. Spannangle. 2000. The statistics of embankment dam failures and accidents. Canadian Geotech. J. 37(5): 1000-1024.

Goto, S., Tatsuoka, F., Shibuya, S., Kim, Y. S., Sato, T. 1991. A simple gauge for local small strain measurements in the laboratory. Soils and Foundation. 31(1): 169-180.

Hardin, B.O., Richart Jr., F. E., (1963): Elastic wave velocities in granular soils, Soil mechanics and foundation Div., ASCE, 89(1), 33-65.

Hight, D. W., Gens, A., Symes, M. J. 1983. The development of a new hollow cylinder apparatus for investigating the effects of principal stress rotation in soils, Geotechnique, 33 (4): $355-383$.

Hird, C. C. \& Yung, P. 1987. Discussion on 'A new device for measuring local axial strains on triaxial specimens'. Geotechnique, 37(3): 413-417.

Lin, K. \& Takahashi, A. 2014. Experimental investigations on suffusion characteristics and its mechanical consequences on saturated cohesionless soil. Soils and Foundations, 54(4): 713-730.

Nguyen, H. \& Koseki, J. 2005. Quasi-elastic deformation properties of Toyoura sand in cyclic triaxial and torsional loadings, Soils and foundations, 45(5), 19-38.

Renuka, I. H. S. \& Kuwano, R. 2011. Formation and evaluation of loosened ground above a cavity by laboratory model tests with uniform sand, Proc. 13th International summer symp, 211-214.

Renuka. S. 2012. Evaluation of ground loosening behavior and mechanical properties of loosend sand associated with underground cavities. Master of Engineering thesis, the University of Tokyo.

Uchida, T., K. Kosugi, T. Mizuyama. 2001. Effects of pipeflow on hydrological process and its relation to landslide: A review of pipeflow studies in forested headwater catchments. Hydrol. Proc. 15(11): 2151-2174.

Wilson, G. V., R. K. Periketi, G. A. Fox, S. Dabney, F. D. Shields, R. F. Cullum. 2007. Soil properties controlling seepage erosion contributions to streambank failure. Earth Surface Proc. and Landforms, 32(3): 447-459.

Wan C.F. \& Fell R. 2004. Laboratory Tests on the Rate of Piping Erosion of Soils in Embankment Dams. Journal of $\mathrm{Ge}$ otechnical Testing Journal, 3(27):295-303. 